\title{
ENTRE GESTOS DE GUARDAR E ATOS DE TESTEMUNHAR: O ARQUIVO DE MEMÓRIAS DA FACULDADE DE EDUCAÇÃO/UFRGS
}

\author{
DÓRIS BITTENCOURT ALMEIDA ${ }^{1}$ \\ ORCID: https://orcid.org/0000-0002-4817-0717 \\ LUCAS COSTA GRIMALDI ${ }^{2}$ \\ ORCID: https://orcid.org/0000-0003-4654-1032
}

\begin{abstract}
RESUMO: $O$ artigo problematiza a constituição do Arquivo de Memórias da Faculdade de Educação/UFRGS. Sua organização se inscreve no campo da História da Educação em interfaces com os postulados da História Cultural, por promover a exploração de experiências educativas, por vezes esquecidos pela historiografia. A temática também filia-se às discussões contemporâneas acerca das práticas arquivísticas. Neste lugar, abrigam-se documentos históricos em diferentes dimensões. Mas "o sabor do arquivo" (Farge, 2009), sem descuidar da documentação oficial, reside no recebimento de arquivos pessoais de professores e de estudantes, muitos deles formados por escrituras ordinárias, e também na produção de memórias orais dos sujeitos que compõem as comunidades acadêmica e escolar. Nesses gestos de guardar, concentram-se esforços para a constituição de um Arquivo Vivo, em que as problemáticas colocadas no tempo presente, transformadas rapidamente em passado direcionam nossas ações e intenções acerca do que guardar, por que guardar, para que guardar, para quem guardar.
\end{abstract}

Palavras-chave:Arquivos, História da Educação, Arquivos Pessoais, História Oral.

\section{BETWEEN SAVING GESTURES AND ACTS OF WITNESS: THE FILE OF MEMORIES OF THE FACULTY OF EDUCATION/UFRGS}

\begin{abstract}
This paper discusses the establishment of the Archive of Memories of the Faculty of Education/UFRGS. Its organization concerns the field of the History of Education, and its relations to the postulates of Cultural History, by enabling the investigation of educational experiences sometimes overlooked by historiography. The theme is also related to contemporary discussions about archival practices.This archive houses many different historical documents. But "the flavor of the archive" (Farge, 2009), without neglecting the official documentation, resides in the receipt of personal files of teachers and students, many of them consisting of ordinary writings, and also in the production of the oral memory of individuals who make up the faculty and school communities. These gestures of keeping focus efforts for establishing a Living Archive, in which the issues raised in the present, which
\end{abstract}

\footnotetext{
1 Professora da Faculdade de Educação e do Programa de Pós-Graduação em Educação/UFRGS. Porto Alegre,RS, Brasil.<Almeida.doris@gmail.com>

2 Doutorando do Programa de Pós-Graduação em Educação/UFRGS. Porto Alegre, RS, Brasil.<lucascgrimaldi@gmail.com> 
quickly turn into the past, direct our actions and intentions about what to keep, why to keep and for whom to keep.

Keywords:Archives, History of education, Personal Files, Oral History.

\title{
ENTRE AHORRO DE GESTOS Y ACTOS DE TESTIMONIO: EL ARCHIVO DE LOS RECUERDOS DE LA FACULTAD DE EDUCACIÓN/UFRGS
}

RESÚMEN: El artículo aborda ele stablecimiento de las memorias de la Facultad de educación/UFRGS. Su organización se suscribe em el campo de la historia de la educación en las interfaces com los postulados de la historia Cultural, fomentando la explotación de las experiencias educativas, a veces pasado por alto por la historiografía. El tema también filia a las discusiones contemporáneas acerca de prácticas archivísticas. En este lugar, estan almacenados documentos históricos en diferentes dimensiones. Pero "el sabor" (Farge, 2009), sin descuidar la documentación oficial, reside en la recepción de archivos personales de profesores y alumnos y muchos de ellos fueran compostos por escrituras ordinarias y también bajo la producción de memorias orales de los sujetos que conforman las comunidades académicas y escolares. Estos gestos para mantener esfuerzos para la creación de um archivo vivo, em el que las cuestiones planteadas em el presente, se convirten rapidamente en el pasado, conducen nuestras acciones e intenciones sobre lo que guardar, por qué mantener, para quién debemos guardarlos.

Palabras clave: Archivos, Historia de laeducación, Archivos personales, Historia oral.

\begin{abstract}
"Essa nova memória é uma memória arquivística, uma memória do papel. Reconhecemos nessa obsessão do arquivo a grande mutação exagerada pelo mito de Fedro que trata da invenção da escrita. Vitória do escriturário no próprio cerne do memorial. Superstição e respeito pelo rastro. O sentimento da perda como no mito platônico torna-se a contrapartida dessa institucionalização da memória. Produzir arquivo é o imperativo da época [...]. O arquivo não é mais o saldo mais ou menos intencional de uma memória vivida, mas a secreção voluntária e organizada e memória perdida" (RICOEUR, 2007, p.410).
\end{abstract}

Neste texto, problematiza-se a constituição do Arquivo de Memórias da Faculdade de Educação da Universidade Federal do Rio Grande do Sul (FACED/UFRGS), localizado na cidade de Porto Alegre. A História da Educação no Brasil ainda carrega muitos silêncios, entre eles estudos sobre memórias das instituições educativas. Ainda é comum que o passado das escolas e das universidades seja pouco conhecido por suas comunidades que, muitas vezes, permanecem indiferentes diante do tempo que se foi. $\mathrm{O}$ esquecimento, marcado por um mutismo em relação ao tempo pretérito, parece impor-se nas relações firmadas entre os sujeitos e as instituições que habitam.

Como é possível manter-se atento e fiel ao passado, se não há o cuidado em guardar vestígios de sua memória? É Paul Ricoeur (2007, p. 40) quem ajuda a refletir acerca dessa questão, ao afirmar que "não temos outro recurso a respeito da referência ao passado senão a própria memória, [...] 
não temos nada melhor que a memória para significar que algo aconteceu, ocorreu, passou, antes que declarássemos nos lembrar dela". Portanto, aqui se postula a importância dos arquivos institucionais como construtos sociais, como refúgios de memórias, com disposição para a "ambição de verdade" (ANHEIN, 2018, p.122), a partir do vínculo material com o passado. Neles, preservam-se "vestígios de práticas humanas" (ANHEIN, 2018, p. 152), por vezes invisibilizadas, mas que, por meio de operações historiográficas, transformam-se em lugares da epistemologia da História.

E o que se pode dizer do Arquivo de Memórias, objeto de análise deste texto? Trata-se de um Arquivo que conserva materialidades de uma instituição de formação docente, a Faculdade de Educação $^{3}$, mas também abriga documentos do Colégio de Aplicação da Universidade (CAp/UFRGS), tendo em vista as aproximações de ambos durante muitos anos ${ }^{4}$. Em uma sala do prédio da FACED, de número 610, construímos um espaço que, por meio da salvaguarda de inúmeros documentos que representam o passado da Faculdade e do Colégio, afirma-se como lugar para socialização de memórias que podem fomentar a pesquisa acadêmica e a consequente produção de versões da história dessas importantes instituições de formação docente e de educação básica. Para além das memórias da Faculdade, a constituição do Arquivo também salvaguarda, em sentido lato sensu, outras memórias da UFRGS $^{5}$ e, por conseguinte, é uma iniciativa de socializar e valorizar o patrimônio educativo da Universidade ${ }^{6}$.

\section{OS SABORES QUE MARCAM OS GESTOS DE GUARDAR}

A organização do Arquivo se inscreve no campo da História da Educação, sendo esta um componente fundamental da história das práticas culturais, em suas interfaces com a História das Instituições Educativas. Também partilha dos postulados teóricos da História Cultural, corrente historiográfica que se distancia de concepções historicistas, reconhece os sujeitos em uma perspectiva que os coloca como partícipes da História de seu tempo, promovendo a exploração de experiências de mulheres e de homens, por vezes esquecidos pela historiografia.

Além dessas localizações epistemológicas, convém ressaltar que a temática também se filia às discussões contemporâneas acerca de Arquivos, discussões essas, por vezes, pouco freqüentes nas pesquisas historiográficas. Nos Arquivos, estabelecem-se complexas relações temporais, em que se entrecruzam as três dimensões do tempo. Lá, conservam-se materialidades pretéritas, que são pensadas no presente, mas visam a perenidade, ou seja, passado, presente e futuro estão entrelaçados nos Arquivos, lugares que acumulam camadas de tempo, como estratos de experiências que permanecem

\footnotetext{
3 A documentação salvaguardada, em sua maioria, provém das atividades administrativas da Faculdade de Educação. Destacamos os documentos dos Departamentos (Departamento de Estudos Básicos, Departamento de Ensino e Currículo e Departamento de Estudos Especializados), do Programa de Pós-Graduação em Educação, da Direção, das Comissões de Pesquisa e dos inúmeros projetos de extensão realizados na instituição.

${ }^{4}$ O Colégio de Aplicação foi inaugurado em 1954, idealizado pela professora Graciema Pacheco, cátedra da disciplina de Didática da Faculdade de Filosofia da URGS. Suas atividades foram realizadas em diversos espaços da universidade, no final da década de 1960, o colégio passou a dividir espaço com a recém-criada Faculdade de Educação. Sobre a história da instituição, ver Lima (2016).

${ }^{5}$ Houve algumas ações pontuais, por parte da Reitoria, na década de 1970, para preservação dos documentos da Universidade, porém não foram levadas adiante, o que culminou em centros de documentações específicos de cada unidade acadêmica.

${ }^{6}$ Nos últimos anos, nota-se a criação de vários departamentos dentro da universidade com a intenção de salvaguardar a documentação histórica, produzir entrevistas e recolher arquivos pessoais. Como Ceme, Museu da UFRGS, Arquivo do Instituto de Artes, entre outros.
} 
ou se modificam em velocidades próprias. Essas concepções permitem ao pesquisador se perguntar "quanto do passado habita no nosso presente?" (KOSELLECK, 2014). Em vista disso, é o presente que se constitui em uma espécie de guia e, assim, conduz nossos gestos de guardar. Em outras palavras, são as problemáticas colocadas no tempo presente, transformadas rapidamente em passados, que direcionam nossas ações e intenções acerca do que guardar, por que guardar, para que guardar, para quem guardar. Ahnein (2018, p. 153) explica que os Arquivos representam "a presença do passado no presente", ou seja, como diz Ketelaar (2018, p. 198), "os arquivos não nos levam até ao passado: preservam o presente para o futuro, ao transmitirem testemunhos e experiências autênticas da atividade humana através dos tempos". Neste sentido, Ahnein (2018) esclarece que a "natureza dos arquivos" é marcada pela "persistência" de buscar traços de outrora que, por meio da salvaguarda, se fazem presentes.

Ao longo dos anos, a Faculdade de Educação e o Colégio de Aplicação constituíram-se, cada qual com suas especificidades, como referências, lugares de discussão e de produção de saberes relacionados à educação. Em 1970, foi criada e instalada a Faculdade, produto da Reforma Universitária de $1968^{7}$, oriunda do Departamento de Educação da Faculdade de Filosofia. Em 1971, estruturou-se o Programa de Pós-graduação em Educação, um ano depois, implantou-se o Curso de Mestrado, com três áreas de concentração: ensino, planejamento educacional e psicologia educacional, reconhecido em 1976, sendo o primeiro a obter reconhecimento do Ministério de Educação e Cultura em todo o Brasil. Logo, ampliou-se o Programa com o Doutorado em Ciências Humanas em Educação com área de concentração: processo ensino aprendizagem em 1977. No Arquivo, também há muitos documentos referentes ao Programa de Pós-graduação ${ }^{8}$. Diante dessas informações, entende-se a FACED e o CAp como "lugares memoráveis" (RICOEUR, 2007), como esteios de identidades sociais, e essas concepções permitiram o desenvolvimento de um projeto de pesquisa intitulado "Memórias e Histórias da FACED e do CAp", que busca, notadamente, por meio de documentos orais e de arquivos pessoais, produzir testemunhos históricos acerca dessas instituições.

Há muitos anos, o prédio da Faculdade de Educação mantém-se como uma espécie de ícone, destacando-se por sua arquitetura modernista, arrojada para os anos $1960^{10}$, em meio ao Campus Central da UFRGS. Ao longo de décadas, uma grande quantidade de pessoas têm circulado por esse espaço, para alguns, é lugar de trabalho, para outros, de estudo. Professores, estudantes, funcionários percorrem todos os dias seus dez andares, sozinhos ou em grupos, cada qual com uma intenção, muitos têm pressa, urgência em seus afazeres cotidianos. Nos arriscamos a dizer que talvez pouco conheçam sobre sua história.

Neste sentido, cabe lembrar que o Curso de Pedagogia foi criado em 1942, na época Faculdade de Educação Ciências e Letras da Universidade de Porto Alegre. Em 1947, a Universidade de Porto Alegre se transformou em Universidade do Rio Grande do Sul, em 1950 passou a fazer parte do

\footnotetext{
${ }^{7}$ Sobre a Reforma Universitária e o contexto da Ditadura Civil-Militar na Faculdade de Educação, ver Almeida; Lima e Silva (2013).

${ }^{8}$ Encontram-se salvaguardadas as minutas e os esboços para institucionalização do Programa de Pós-Graduação em Educação, além de alguns documentos da primeira equipe coordenadora. Destacamos que guardamos uma pequena parte da documentação, pois grande parte do acervo do PPGedu permanece sob a guarda do pós-graduação.

${ }^{9}$ Este projeto teve início em 2010 com a organização do acervo documental da FACED e a produção de um acervo de memórias orais, a partir de entrevistas com antigos professores. Estas ações procuram dar visibilidade às diferentes memórias que constituíram a Faculdade de Educação da UFRGS.

10 Sobre o prédio da Faculdade de Educação, ver Grimaldi e Almeida (2018).

Educação em Revista|Belo Horizonte|v.36|e223025|2020
} 
sistema federal e, em 1970, assumiu a sigla UFRGS, mesmo ano de fundação da Faculdade de Educação. Portanto, as memórias materiais do que hoje se chama Faculdade de Educação, embora muito tenha se perdido, remontam a outros espaços e temporalidades, remontam a um tempo em que nem mesmo a Universidade era federalizada.

O trabalho desenvolvido tem se pautado por uma proposta de reorganização e reflexão constante acerca dos sentidos da construção de um Arquivo de Memórias institucional ${ }^{11}$. Aqui partilhase da orientação de Ketelaar (2018, p. 196) ao defender que "arquivar e arquivamento são muito mais do que classificar documentos nos arquivos, mas abrangem todas as fases, desde a coleta dos documentos, de sua gestão e utilização até disponibilização". Sendo assim, cabe lembrar que, ao iniciarmos as atividades, há alguns anos, encontramos os documentos produzidos pelos diversos setores administrativos da Faculdade e pelo Colégio em uma situação de abandono e nenhum tratamento arquivístico. Em uma espécie de depósito, estavam caixas de papelão com muitos papéis empilhados, dispostas em estantes, umas sobre as outras, sem possibilidade de deslocamento. Percebeuse logo a urgência de uma ação que preservasse o quase deteriorado acervo documental da FACED e do CAp. Esses testemunhos da vida institucional estavam armazenados em condições adversas, por conta da localização em instalações inadequadas e insalubres que colocavam em risco tanto a existência dos documentos quanto a saúde dos que com eles tinham contato. O descuido com essa memória, incorporada em suportes antigos, contribuía para o esquecimento do cotidiano vivido por inúmeras pessoas: professores, estudantes, diretores, funcionários administrativos, bibliotecários, entre outros ${ }^{12}$.

Mas por que enfrentar o desafio de construir um Arquivo de Memórias institucional? O que nos moveu? Como pesquisadores da História da Educação, nosso olhar está interessado em resguardar documentos que, se examinados, possam contar histórias. Todavia, como professores de História da Educação, também nos importa o alcance formativo deste lugar, ou seja, trabalhamos no sentido de fomentar entre os estudantes dos Cursos de Pedagogia e das demais licenciaturas, o desejo de melhor conhecerem a História da UFRGS, pelos documentos lá salvaguardados. Essa prática contribui para que os estudantes percebam o potencial da História da Educação como campo de investigações, para além de componente disciplinar.

Conforme ArletteFarge (2009), os Arquivos são vestígios de lugares singulares e complexos que precisam ser desvendados em sua materialidade como um mar no qual se mergulha e onde o afogamento pode ocorrer. Nestes espaços, podemos "captar as falas" e reconhecer "rostos e sofrimentos, emoções e poderes criados para controlá-los” (FARGE, 2009, p.94). Diana Vidal (2005, p. 19), com base nas observações de Pierre Nora (1993), destaca os Arquivos como lugares de memória, lugares duplos enquanto locais de guarda de seus acervos, mas, ao mesmo tempo, "constantemente abertos a novas leituras acerca do passado e do presente". Lugares que necessitam de tratamento adequado, com organização e descarte, entendidos como procedimentos complementares, situados dentro de um processo técnico, no campo da arquivística, que exige, dessa forma, o diálogo entre historiadores e arquivistas.

\footnotetext{
${ }^{11}$ Cotidianamente, realizamos as seguintes atividades no arquivo: Higienização, catalogação e acondicionamento dos documentos; trabalho de análise e identificação da tipologia documental; Recebimento e organização de arquivos pessoais de professores.

12 Além da organização do acervo documental, do recebimento de arquivos pessoais e da criação do arquivo de Memória Oral, realizamos ações de socialização da memória desta instituição como Exposições no evento UFRGS Portas Abertas, participação na organização dos eventos comemorativos da instituição (Aniversário de 45 anos da FACED). 
O passado é alteridade, somos sabedores da impossibilidade de restituir o tempo que se foi. Tendo Certeau (2008, p. 35) como referência, a única certeza que nos acompanha é que "não se poderia reacender o que a vida apagou", então o que nos mobilizou a produzir este Arquivo é um desejo de guardar memórias das instituições e de seus sujeitos, "restaurar um esquecimento, e encontrar os homens (e mulheres) através dos traços que eles deixaram” (CERTEAU, 2008, p.35), conferir movimentos a algo que estava parado, em um estado de quietude. Assim, longe de pensar no Arquivo da FACED e do CAp como algo morto, o que se vê por lá é muita vida, observada no trabalho cotidiano de professores, estudantes do pós-graduação, bolsistas de iniciação científica que se envolvem com tarefas de higienização e catalogação de documentos, produção de entrevistas, recebimento de arquivos pessoais, além da pesquisa individual que promove sentido acadêmico às atividades arquivísticas.

E quais outros pressupostos orientam o trabalho de salvaguarda documental? Escolano (2017) explica que todos os elementos que compõem as instituições "falam”, evidenciam valores e transmitem informações acerca da escola, da educação e de suas relações com a sociedade, em cada contexto histórico. Para Pierre Nora, "[d]esde que haja rastro, distância, mediação, não estamos mais dentro da verdadeira memória, mas dentro da história”. A memória, para o autor, se enraíza no concreto, no espaço, no gesto, na imagem, no objeto (NORA, 1993, p. 9). Viñao Frago(1995) observa que a cultura escolar refere-se ao conjunto de aspectos institucionalizados, ao cotidiano do fazer escolar, aos modos de pensar, aos objetos escolares, a materialidade física, enfim, a cultura escolar é toda a vida escolar. O estudo da cultura material escolar não pode ser entendido como simples reflexo das relações sociais. Por outro lado, os modos de uso dos objetos, sua escolha, a receptividade, ausências e presenças de utensílios, os processos de aquisição e procedência, entre outros, são elementos que participaram ativamente da criação, operação, manutenção e/ou desativação das experiências escolares.

Portanto, no Arquivo de Memórias nos preocupamos em proteger vestígios da Faculdade e do Colégio, a mirada é para aquilo que, por diferentes motivos, conseguiu sobreviver ao tempo, considerados por Escolano (2017) "os lixos da escola", materiais, via de regra da ordem do banal, mas que podem promover novas inteligibilidades acerca do passado da educação.

Em toda a constituição arquivística, estabelecem-se disputas entre o que importa conservar. Entendemos que tudo depende das convicções epistemológicas daqueles que se propõem a este trabalho. Afinal, os Arquivos não falam por si mesmos, reverberam interesses e esperanças daqueles que se propõem a organizá-los. Neste Arquivo que aqui discutimos, abrigam-se inúmeros documentos históricos ${ }^{13}$, produzidos pelas instituições ao longo dos anos, em suas mais diferentes instâncias. Mas para nós, o "sabor do Arquivo", valendo-se da metáfora de ArletteFarge (2009), sem descuidar da organização documental oficial ${ }^{14}$, reside no recebimento de arquivos pessoais, formados por documentos diversos, muitos deles escrituras ordinárias, representativos da Faculdade e do Colégio

\footnotetext{
${ }^{13}$ Entre os documentos históricos podemos destacar o acervo da extinta Faculdade de Filosofia da UFRGS (1942-1970). Neste, constam documentos administrativos do curso de pedagogia, periódicos, alguns documentos do Grêmio Estudantil, diplomas, certificados e processos disciplinares do período da DitaduraCivil-Militar. Além disso, também salvaguardamos as atas de criação da Faculdade de Educação e do Programa de Pós-Graduação, as atas das reuniões departamentais e dos colegiados.

${ }^{14}$ Neste sentido, contamos com o apoio das arquivistas da universidade e toda documentação proveniente dos setores administrativos passa pela triagem a partir da Tabela de Temporalidade de Documentos do Conselho Nacional de Arquivos - CONARQ.
} 
e também na produção de memórias orais dos sujeitos que compõem as comunidades acadêmica e escolar. Esses são os nossos gestos de guardar em um Arquivo Vivo, constituído por "documentos silenciosos" da Universidade, que "hoje querem se fazer ouvir" (PINSKY, 2005, p.7).

É nesta perspectiva que muitos artefatos encontram espaço de acolhida e passam a habitar o Arquivo de Memórias da FACED/CAp, que pode ser compreendido como uma espécie de refúgio, em meio às pressões do cotidiano de estudo e de trabalho. Como lugar, garante "vínculos entre passado, presente e futuro" (Anhein, 2018, p. 131), afinal mantém-se uma presença de testemunhos de tempos pretéritos que aspiram a presença também no futuro. Há o interesse pelos "resíduos da escola que guardam segredos que afetam os silêncios da História da Educação" (Escolano, 2017, p.38). Na esteira desse pensamento, Nora diz que "os lugares de memória são antes de tudo restos" (1993, p.12), restos do que passou, "fragmentos de verdade, ofuscantes de nitidez e de credibilidade" (Farge, 2009, p. 27). É assim que folhas de papel avulsas e aparentemente com pouco sentido de organização, cadernos íntimos, cadernos de planejamento de aula, agendas, trabalhos de estudantes, fotografias, convites e discursos de formatura, bilhetes dizem muito da cultura destas instituições educativas. Todos eles são recebidos, higienizados e guardados para posterior consulta de pesquisadores. Entendemos a produção e manutenção desses registros como uma forma de atestado de nossas existências, que nos situam no mundo, sendo práticas do "arquivamento do eu" (ARTIÈRES, 1998), de construção de si mesmo e de resistência.

Para além do interesse pelos arquivos pessoais, também desenvolvemos um arquivo de memórias orais de professores, de funcionários e de estudantes egressos, em constante ampliação ${ }^{15}$. Por meio da metodologia da História Oral, produzimos entrevistas e, nestes contatos, procuramos instar cada entrevistado a remexer no sen passado, buscar velhos papeis guardados acumulados pelo tempo e, assim, fazerem suas doações. Esse não é um trabalho fácil, pois, na maioria das vezes, as gestualidades de entregar coisas que são nossas, que são íntimas, demandam sensibilidade e confiança naquele que se torna uma espécie de guardião das memórias do outro. Na sequência, o texto procura problematizar a produção desses arquivos, tanto orais, quanto pessoais que, com a anuência dos sujeitos implicados, passam a compor o Arquivo de Memórias da FACED e do CAp.

\section{ENTRE DIÁRIOS, CADERNOS, REDAÇÕES E OUTROS...: A RIQUEZA DOS ARQUIVOS PESSOAIS}

Há algum tempo, movidos por reflexões teóricas acerca do tema, apostamos nos arquivos pessoais, aparentemente silenciosos, como potentes documentos da ordem do sensível que trazem, de diferentes modos, memórias institucionais e de seus sujeitos. Sue McKemissh (2013, p. 244) os considera como registros que oferecem "testemunhos de nossas interações com os outros, no contexto de nossas próprias vidas e do lugar que ocupamos nas deles". São, assim, "provas de nossa existência, de nossas atividades e experiências". Reitera-se aqui o significado do Arquivo de Memórias em questão constituir-se como espaço de acolhida dessas "práticas de arquivamento do eu” (ARTIÈRES, 1998), respeitando as idiossincrasias dos modos como cada sujeito organizou suas relíquias. Há alguns que se

\footnotetext{
${ }^{15} \mathrm{O}$ arquivo de memórias orais da FACED conta com mais de 50 entrevistas com professores, funcionários e estudantes egressos do Curso de Pedagogia, disponíveis para consulta local.

Educação em Revista|Belo Horizonte|v.36|e223025|2020
} 
constituem de cadernos íntimos, outros formados por conjuntos de papéis variados, e ainda aqueles que são cadernos de planejamento escolar. Pode-se dizer que todos, em que pesem suas especificidades, são dotados de complexidade, exigem atenção nas investigações que se debruçam sobre eles. É preciso reiterar o quão custoso pode ser doar papéis de foro íntimo, muitas vezes, de difícil desapego. Delicadeza e amabilidade são atributos importantes que devem se colocar nessa relação que se estabelece entre aquele que faz a doação e aquele que, em nome da instituição, a recebe. Ao acolher esses artefatos, procuramos manter uma atitude de reverência diante de quem os entrega. Consideramos tais doações como verdadeiros relicários, pois poucos sobrevivem à sua vida útil, tendo em vista que, na maioria das vezes, o descarte costuma ser seu destino final. Neste sentido, Cunha reflete acerca desses documentos, concebidos como "relíquias" e explica que "trazem consigo histórias, acontecimentos, lembranças, memórias, pois que estão imbuídas de significados e de qualidades de representação que vão além de sua situação original" (CUNHA, 2007, p. 84).

Por que e por quem esses objetos foram guardados? Quais as condições e motivações que permearam a concessão para um Arquivo público? Ketelaar (2018) explica a importância de reconstruir o itinerário dos documentos desde sua criação até o momento de habitarem as instituições arquivísticas, quando adquirem, desse modo, um novo estatuto. Neste sentido, cabe dizer que os atos de doação, em geral, não são espontâneos, isso seria pouco provável, por vezes, são nas entrevistas que acontece uma possibilidade efetiva de sensibilizar para a futura doação. Em outros momentos, é remexendo em gavetas e armários dos professores na Faculdade que preciosidades para a História da Educação são identificados ${ }^{16}$.

Os arquivos pessoais "nascem da desordem, eles também supõem mãos que manipulam e classificam os documentos, olhos que vigiam o escrito, cheiros que despertam memórias" (CUNHA, 2015, p.16). No nosso Arquivo, esses conjuntos documentais são importantes, poderíamos dizer que são nossas meninas dos olhos. Percebe-se que muitos deles foram fabricados com artesania, ao longo de anos, em que estão implicadas dimensões autobiográficas na sua construção. Arquivar é um modo de testemunhar, de deixar registradas nossas memórias, de reconhecer as "huellas escritas" (CASTILLO GOMEZ, 2003) de pessoas comuns. Embora carreguem uma marca institucional, às vezes tênue, tais documentos são dotados de algo pessoal. Trazendo mais uma vez Sue McKemmish (2013) para a discussão, esses artefatos constituem-se em "provas de mim”, mas também "provas de nós”, ou seja, representam indícios da cultura institucional especificamente e das temporalidades em que se inscrevem. Entre os arquivos pessoais ${ }^{17}$ destacam-se cadernos, tanto íntimos quando de planejamentos. Notadamente em relação a esse tipo documental, enquanto fontes para o campo da História da Educação, reforça-se que houve um tempo em que não tinham a notoriedade que hoje possuem. Mas, diante do contexto da ampliação da noção documental, esse suporte de escrita passou a ser valorizado, em sua interface com "a preocupação dos historiadores em examinar o vivido na sala de aula” (MIGNOT, 2008, p. 7). Gomez (2012) observa o quanto vem se alargando o interesse por esses

\footnotetext{
${ }^{16}$ Comumente, os professores da FACED e do CAp guardam seus materiais de estudo e pesquisa em armários localizados nos corredores da instituição. Muitos professores, após seu processo de aposentadoria, se esquecem de esvaziar esses armários, por isso, muitas vezes somos chamados para realizar uma triagem nesses documentos "esquecidos" que acabam constituindo ricos arquivos pessoais.

17 Alguns documentos que temos nos arquivos pessoais: papeis doados pelo professor BalduinoAndreola, agendas da professora Luzia Garcia de Mello, cadernos de planejamento da professora Isabel Loss, memoriais das discentes do Curso de Pedagogia, trabalhos de alunos, fotografias, cartas e outros. 
documentos, como uma dívida da História da Educação para com os materiais da ordem do comum, e, ao mesmo tempo, enfatiza a "inquietude por sua busca".Afinal, sabemos que não são produzidos com vistas à perenidade. Tal situação reforça o entusiasmo dos pesquisadores ao se depararem com esses conjuntos documentais. São como o encontro de tesouros que podem, enfim, serem explorados pela historiografia.

\section{ENTRE A VOZE A ESCRITA: O ARQUIVO DE MEMÓRIAS ORAIS}

Antes mesmo da atenção para com os documentos pessoais, emergiu uma vontade de construir outro arquivo, ancorado em memórias orais daquelas e daqueles que viveram, na Faculdade e/ou no Colégio, um tempo importante de suas formações como estudantes, funcionários e professores. Justino Magalhães (1999) explica as profundas aproximações entre as memórias das instituições educativas e seus sujeitos, em suas palavras "uma memória constituída por relatos e representações, simbólicas ou materiais [...]. Uma memória integrada nas práticas do cotidiano (MAGALHÃES, 1999, p.69)".

Para tanto, elegemos a História Oral como metodologia. Sensibilidade, cumplicidade, respeito, atenção à fala do outro (ERRANTE, 2000), além de solidariedade são elementos essenciais de quem escolhe esses caminhos de pesquisa que valorizam as narrativas de diferentes sujeitos. A vivência de tantas entrevistas permite dizer que o estabelecimento da "ponte interpessoal" (ERRANTE, 2000, p.152) tem seu início antes do primeiro encontro, por e-mail ou contato telefônico, quando se operam as primeiras aproximações. A partir daí a forma como a pessoa recebe o entrevistador, a sua preparação para aquele momento, o grau de disponibilidade para falar, tudo isso contribui e consolida as possibilidades de interação. A metáfora da ponte pode valer para lembrar a importância da busca pela constituição de uma relação de confiança entre aquele que indaga e aquele que se propõe a falar e, segundo Zago (2003, p. 302), é condição sinequa non da produção de dados significativos, enfim, garantia da fecundidade das entrevistas.

Servidores e estudantes egressos carregam em suas memórias os percursos, não só da instituição, mas dos processos pelos quais historicamente passou a educação em âmbito nacional e regional, o que justifica entrevistá-los, evitando, assim, o apagamento das práticas educativas relativas a um tempo e lugar. Trata-se, então, da produção de memórias de uma instituição de formação de professores e de um colégio em que se articulam vivências sociais e educativas no contexto em que ocorreram, permitindo interconexões entre as diferentes histórias vividas pelos sujeitos e as condições materiais nas quais se produziram determinados processos educativos.

Entende-se que as pesquisas que operam com documentos orais oferecem uma dimensão singular de aproximação com o tempo passado. Os encontros com os narradores, quando se busca capturar instantes de memórias apostando no poder do "pequeno milagre do reconhecimento" (RICOEUR, 2007), em muitos casos, constituem momentos de fecundidade das relações humanas. Sabemos que o ambiente onde acontecem as entrevistas deve ser avaliado com cuidado, procurando garantir que haja o mínimo de interferências e que o lugar escolhido promova a imersão no passado. Para a constituição deste arquivo, deixamos que o entrevistado decida o lugar que, na maioria das vezes, acaba sendo nas dependências da própria Faculdade. Tal escolha produz um alto poder evocativo das memórias, estar no prédio, portanto, facilita o trabalho de lembrar. Conversar com as pessoas, perceber 
como se movimentam no espaço, perceber suas sensações ao procurar antigas referências a lugares que, por vezes, não existem mais, ao buscar colegas que talvez já nem estejam nos antigos postos, escutá-los, observá-los constituem-se em momentos preciosos, quando podemos nos acercar das marcas de um outro tempo, que nos escapa, por não termos vivido. O sentido de humanidade promovidopela História Oral (PRINS,1992) calafundo nos pesquisadores, que, longe de entenderem que exista qualquer redenção na metodologia, encontram no seu uso novas formas de compreensão do passado, formas com as quais se identificam.

Há que se considerar que, no documento oral,trabalha-se com a interação da narrativa, da imaginação e da subjetividade. A fala é suscetível às vicissitudes de cada momento, todavia, não significa que a memória seja intangível, pelo contrário, permite a aproximação de verdades que se quer produzir sobre o vivido. E guarda o mérito de trazer à tona nuances do passado, que podem estar esquecidas e que, por vezes, se encontram inatingíveis em outros documentos, além de dar visibilidade aos sujeitos na construção da história. Interessa, pois, o fio narrativo que cada entrevistado escolhe para contar sua história. "As entrevistas são eventos que contam" (ERRANTE, 2000, p. 143).Esta máxima acompanha o desenvolvimento da produção do arquivo de memórias orais, que é contínuo, sempre aberto a novas possibilidades de produção de narrativas. As memórias são labirínticas, plurais e indomáveis, portanto, por mais que exista um roteiro de entrevista, por mais que o pesquisador se esforce para conduzir este evento de modo direcionado, é aquele que fala quem decide o rumo da conversa. Ele escolhe o que quer falar. "Narrativas de memória são narrativas de identidade" (ERRANTE, 2000), assim, entende-se o quanto as memórias desses sujeitos professores da FACED assumem o tom autobiográfico, em que se estreitam as relações entre memória e sentimento de identidade. "A memória é um elemento constituinte do sentimento de identidade, tanto individual como coletiva, na medida em que ela é também um fator extremamente importante do sentimento de continuidade e de coerência de uma pessoa ou de um grupo em sua reconstrução de si." (POLLAK, 1992, p.29).

Outra questão que emerge nessa discussão é pensar nas possíveis potências e fragilidades dos arquivos de memória oral. Afinal, para quem pesquisa, este é um trabalho com História Oral? Aqui se postula que sim, apesar das interdições, pois o pesquisador não produziu o documento, ou seja, não participou do evento da entrevista, nem mesmo da construção do roteiro. Tem acesso à transcrição da entrevista e aos áudios. Mas, mesmo assim, está em contato com uma fonte que tem sua origem na oralidade que foi transposta para a cultura escrita, mas não perdeu sua especificidade. Produzir memórias orais também é prioridade em nossos gestos de guardar. Por meio da conservação escrita, as vozes dos sujeitos narradores permanecem em um estado de perenidade. Seriam esses arquivos um modo de eternizar a presença de servidores e estudantes no presente e no futuro? Acreditamos que sim.

Até 2018, desenvolveram-se 46 entrevistas com professores que abordaram a história de vida, enfatizando a formação profissional, as vivências no ensino superior, o ingresso na Faculdade de Educação e a trajetória construída na Universidade. Cabe salientar que a busca pelos entrevistados obedeceu a certa intencionalidade, ou seja, o critério fundamental foi ter muitos anos de vivência na Faculdade. Assim, foram vários os questionamentos que se apresentaram aos envolvidos. Quem são eles? Quais percursos realizaram até o ingresso na Faculdade ou no Colégio? Que lugares ocuparam ao longo dos anos de trabalho na Faculdade ou no Colégio? Como desenvolveram seu ofício? Quais as 
circunstâncias históricas vividas na FACED perpassaram suas vidas? Que aspectos foram preponderantes em seus percursos? Em que medida assimilaram os discursos educacionais vigentes e como essa assimilação interferiu na composição de suas identidades? Que significados as experiências docentes lhes deixaram? Quais pessoas foram importantes ao longo da História da Faculdade?

Também foram desenvolvidas seis entrevistas com estudantes egressos do Curso de Pedagogia e duas com funcionários da Faculdade. Salientamos que algumas dessas entrevistas foram produzidas no contexto de pesquisas de Mestrado, Iniciação Científica e monografias de conclusão de Curso de Pedagogia. Sendo três entrevistas do projeto de iniciação científica "Memórias da presença negra na Faculdade de Educação", três entrevistas sobre memórias de antigos estudantes da Faculdade, três entrevistas sobre memórias da professora Mérion Campos Bordas e cinco entrevistas com memórias de professoras do Colégio de Aplicação.

Portanto, algumas temáticas evocadas nas entrevistas são: biografias, Colégio de Aplicação, greves de professores, ditadura-civil militar; a década de 1970 na FACED, participação e política nos anos 1980/90; a emergência doPós-estruturalismo, da temática das Relações de Gênero na FACED, o Programa de Pós-Graduação em Educação, relações de pertencimento. Destacamos a temática das relações com o espaço da Faculdade como a mais recorrente no processo de evocação de memórias, afinal como diz Paul Ricoeur (2007), os lugares são “memoráveis". Percebemos o espaço relacionado às transgressões dos estudantes, como local de pertencimento, mas também como espaço de disputa, principalmente entre o Colégio de Aplicação e Faculdade de Educação. Transgressões quando ressentiam-se da presença dos governos militares e depois nas lutas pelas melhorias no ensino superior público, ainda se manifestam talvez de forma mais sutil, mas não menos evidente. Os laços que os aproximavam estão presentes ainda hoje, pois a FACED continua sendo um espaço de muitas lutas políticas pela educação, lutas que se desdobram em diferentes nuances. Cabe enfatizar a última pergunta que, comumente, fazemos aos nossos entrevistados: Como você percebe a Faculdade no futuro? Muitos a projetam como um esteio, relembrando o passado de lutas pela educação pública plural, democrática e de qualidade. A riqueza deste arquivo de memórias orais reside no entrecruzamento entre passado, presente e futuro da educação brasileira.

\section{UM TRABALHO QUE CONTINUA NOS GESTOS DE GUARDAR}

Retomando a epígrafe escolhida para abertura do texto, Paul Ricouer nos fala deste tempo, marcado pelo imperativo de produzir arquivos, que se traduz em "uma memória arquivística, uma memória do papel” (RICOEUR, 2007, p.410). Neste texto, discutiu-se a constituição do Arquivo de Memórias da Faculdade de Educação e do Colégio de Aplicação/UFRGS, considerando questões epistemológicas implicadas na construção desse lugar de arquivamento de memórias institucionais e de seus sujeitos, sobretudo memórias de professores e de estudantes.

São fecundas as relações que se estabelecem entre o passado educacional e o presente que vivemos. Essas inter-relações despertam o interesse pela História da Educação e demonstram o significado em estudar o pensamento e os contextos de outras épocas educacionais. A ação do tempo tende a apagar rastros, portanto os gestos de guardar são verdadeiras atitudes de resistência diante de um presentismo que se instala, em que parece haver pouco espaço para reflexões acerca do passado. 
Guardar e produzir memórias também são modos de reconstruir processos identitários das instituições educativas e de seus sujeitos, para que não se esqueçam, para que não se apaguem.

Entre as decisões acerca do que guardar e do que descartar, várias questões se impõem. Primeiramente, as leis arquivísticas, com suas normativas que determinam, pelas tabelas de temporalidade, o que se deve preservar. Por outro, nossas sensibilidades conduziram o trabalho no Arquivo de Memórias, promovendo um destaque para documentos orais e pessoais de sujeitos que foram marcados pela Faculdade e/ou pelo Colégio.

Ainda cabem reflexões acerca dos desafios que se colocam para qualquer instituição, notadamente as públicas, que enfrentam a implantação de Arquivos de Memórias. Quais as condições, em sentido lato sensu, das instituições, condições estruturais, financeiras? Quais são as prioridades, os campos de disputas que se estabelecem? Quais as condições de trabalho/demandas de estudantes e de professores? Para que e para quem guardar? Para a instituição, comunidade, pesquisadores? Qual é o passado que se deseja preservar? Qual a formação desenvolvida que sensibilize para o guardar? Como envolver professores, estudantes, comunidade nos gestos de guardar?Como fomentar sentidos pedagógicos no trabalho em um Arquivo de Memórias? Todas essas não são perguntas fáceis de serem respondidas, muito menos comportam respostas únicas. Exigem, isso sim, meditação contínua daqueles envolvidos com essas questões. Afinal, como diz o poeta"guardar uma coisa não é escondê-la ou trancá-la, em cofre não se guarda coisa alguma, em cofre perde-se a coisa à vista, Guardar uma coisa é [...] admirá-la, isto é, iluminá-la ou ser por ela iluminado [...], é velar por ela, isto é, estar acordado por ela" (ANTONIO CÍCERO).

Encerramos este escrito lembrando a incompletude do compromisso com este Arquivo, considerando que, para além de espaço contemplativo do passado, é lugar em que diferentes ações se desenvolvem. Segundo Ketelaar (2018, p. 193), eles “jamais se fecham, jamais estão completos, cada indivíduo ou cada geração pode ter sua própria interpretação dos arquivos, tem o direito de reinventar e de reconstruir sua visão do passado". Concordando com Cunha (2007), destacamos o significado de institucionalizar arquivos escolares e de Universidades em suas interfaces com a preservação da memória e com o patrimônio cultural histórico educativo. Assim, é possível aproximar-se dos "mistérios da escola e as incertezas de seus labirintos individuais e coletivos considerados refinados artesanatos" (CUNHA, 2015, p.295). Por fim, acreditamos na potência dos gestos de guardar também como forma de resistir ao esquecimento, principalmente aquele produzido pela aceleração do tempo, pelo presentismo, tal qual afirma Hartog (2006). Afinal, nas últimas décadas "a confiança no progresso se substituiu à preocupação de guardar e preservar: preservar o que e quem? Este mundo, o nosso, as gerações futuras, nós mesmos" (HARTOG, 2006, p.270-271).

\section{REFERÊNCIAS}

ALMEIDA, Doris Bittencourt; LIMA, Valeska Alessandra de; SILVA, ThaiseMazzei da. A constituição da faculdade de educação/UFRGS em tempos de ditadura militar (1970-1985). Revista Tempo e Argumento, Florianópolis, v. 5, n.10, p. 317 - 346, jul./dez. 2013.

ANHEIM, Etienne. Arquivos singulares - o estatuto dos arquivos na epistemologia histórica. Uma discussão sobre A memória, a história, o esquecimento de Paul Ricoeur. In: NEDEL, Letícia e 
HEYMANN, Luciana (Org.). Pensar os Arquivos: uma antologia. Rio de Janeiro: FGV Editora, p.121-154, 2018.

ARTIÈRES, Philippe. Arquivar a própria vida. Revista Estudos Históricos, São Paulo,n. 21, p. 9 34, jan./jun. 1998.

CERTEAU, Michel de. A escrita da história. Rio de Janeiro: Forense Universitária, 2008.

CICERO, Antonio. Guardar. Disponível em: https://www.pensador.com/autor/antonio_cicero/. Consulta em 23/04/2019.

CUNHA, Maria Teresa Santos. No tom e no tema: escritas ordinárias na perspectiva da cultura escolar (segunda metade do século XX). In: BENCOSTTA, Marcus Levy (Org.). Culturas escolares, saberes e práticas educativas. São Paulo: Cortez, 2007. p.79-99.

CUNHA, Maria Teresa Santos. Acervos Escolares no Tempo Presente. Revista História da Educação, Porto Alegre, v. 18, n.47, p. 293-296, set./dez. 2015.

ERRANTE, Antoinette. Mas afinal, A Memória é de Quem? Histórias orais e modos de lembrar e contar. Revista História da Educação, Porto Alegre, v. 4, n. 8, p. 141-174, jul./dez.2000.

ESCOLANO, Benito, Agustin. A Escola como Cultura: experiência, memória e arqueologia. Editora Alinea: Campinas, 2017.

FARGE, Arlette. O Sabor do Arquivo. São Paulo: EDUSP, 2009.

GOMEZ, Antonio Castillo. Das mãos ao arquivo. A propósito das escritas das pessoas comuns.

Percursos, Florianópolis, v.4, n.1, p. 223-250, jul. 2003.

GOMEZ, AntonioCastillo. Educação e cultura escrita: a propósito dos cadernos e escritos escolares.

Educação, Porto Alegre, v. 35, n. 1, p. 66-72, jan./abr. 2012.

GRIMALDI, Lucas Costa; ALMEIDA, Dóris Bittencourt. “A TORRE AZUL”: memórias de espaços escolares pelas narrativas de estudantes e professores (1954-1996). Revista Educação em Questão, v. 56, n. 48, p.140-170, abr./jun. 2018.

HARTOG, François. Tempo e Patrimonio. Varia História. Belo Horizonte., v.22, n.36, p. 261-273, jul./dez. 2006.

KETELAAR, Eric. (Des)construir o arquivo. In: NEDEL, Letícia e HEYMANN, Luciana (Org.). Pensar os Arquivos: uma antologia. Rio de Janeiro: FGV Editora, 2018. p.193-206.

KOSELLECK, Reinhard.O conceito de História. Belo Horizonte: Autêntica, 2014.

LIMA, Valeska Alessandra de. O Colégio de Aplicação da UFRGS: práticas educativas adormecidas entre o arquivo e a memória oral (1954-1981). 2016. 150f. Dissertação (Mestrado em Educação). Porto Alegre: Universidade Federal do Rio Grande do Sul, 2016.

MAGALHÃES, Justino. Contributo para a história das instituições educativas - entre a memória e o arquivo. In: FERNANDES, Rogério; MAGALHÃES, Justino. Para a história do ensino liceal em Portugal - actas dos colóquios do I centenário da reforma de Jaime Moniz(1894 - 1895). Braga: Secção de artes gráficas das oficinas de trabalho, p.71-89, 1999.

MCKEMMISH, Sue. Provas de mim... novas considerações. In: TRAVANCAS, Isabel; ROUCHOU, Joelle. HEYMANN, Luciana (Org.). Arquivos pessoais: reflexões multidisciplinares e experiências de pesquisa. Rio de Janeiro: FGV, p.15-34, 2013.

MIGNOT, Ana ChrystinaVenancio (Org.). Cadernos à vista: escola, memória e cultura escrita. Rio de Janeiro: EdUERJ, 2008. 
NORA, Pierre. Entre memória e História: a problemática dos lugares. Projeto História. São Paulo, v.10, p. 7-28, jul./dez. 1993.

PINSKI, Carla Bassanezi. Apresentação. In: PINSKI, Carla Bassanezi (Org.) Fontes Históricas. São Paulo: Contexto, 2005. p.7-8.

POLLAK, Michael. Memória e Identidade Social. Estudos Históricos. Rio de Janeiro, v.5, n.10, p. 200-212, 1992.

PRINS, Gwyn. História Oral. In: BURKE, Peter (Org.). A escrita da História: novas perspectives. São Paulo, Editora da Universidade Estadual Paulista, 1992, p. 163-198.

RICOEUR, Paul. A memória, a história, o esquecimento. Campinas: Editora da UNICAMP, 2007.

MCKEMMISH, Sue. Provas de mim... novas considerações. In: TRAVANCAS, Isabel; ROUCHOU, Joelle. HEYMANN, Luciana (Org.). Arquivos pessoais: reflexões multidisciplinares e experiências de pesquisa. Rio de Janeiro: FGV, 2013. p. 15-35.

VIDAL, Diana. Culturas Escolares. Estudo sobre práticas de leitura e escrita na escola pública primária (Brasil e França, final do século XIX). Campinas, Autores Associados, 2005.

VIÑAO FRAGO, Antonio. Historia de la educación y historia cultural. Posibilidades, problemas, cuestiones. Revista Brasileira de Educação, p. 63-82, set./out./nov./dez. 1995.

ZAGO, Nadir. A entrevista e seu processo de construção: reflexões com base na experiência prática de pesquisa. In: ZAGO, Nadir; CARVALHO, Marília Pinto de VILELA, Rita Amélia Teixeira (Org.) Itinerários de pesquisa: perspectivas qualitativas em sociologia de educação. Rio de Janeiro: DP\&A, 2003. p. $287-309$. 